\title{
Language Learning Disabilities: How Can I Help My Students with Dyslexia?
}

\author{
Eka Apriani \\ IAIN Curup \\ ekaapriani_90@ymail.com \\ Dadan Supardan \\ UIN Mataram \\ dadan.supardan@uinmataram.ac.id
}

\begin{abstract}
This paper showed the language learning method in teaching disabilities students with dyslexia problem. In this article the main focus is how to teach the dyslexia students in reading skill. Furthermore, in this study also explain the causes of dyslexia which are neurological and cognitive factor. Beside of that, the characteristics of children with dyslexia divided into two stages: early childhood (preschool or kindergarten, Grade 1-3, and Grade 4-8) and middle childhood with dyslexia (High school, college, and adult). And the last teacher has important role in teaching for the students with reading disabilities and difficulties (dyslexia). Teacher can guide the student in learning, give them an interesting activities by using good strategy.
\end{abstract}

Keyword: Reading Skill, Dyslexia, and Language Learning.

\section{INTRODUCTION}

Brain has an important role in language learning. The function of brain is controls all behavior, including language. Language is vital to individual success, and diseases affecting language can cripple a person in his or her family or social group (Caplan, 1995). The brain disorder is one aspect that can effect the way of students in learning language. Brain

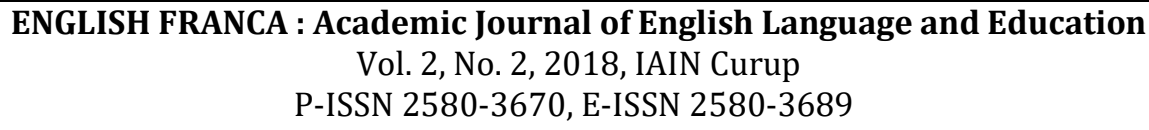


disorder or it can be said that learning disability means that difficult learning of students in an academic area. Learning disability is not a single disorder, but is a general category of special education composed of disabilities in any of seven specific areas: listening, speaking, basic reading skills, reading comprehension,written expression, mathematics calculation, andmathematical reasoning (Lyon, 1996). According to Saskatchewan Learning (2004), there are four types of learning disabilities: written expression disorder, mathematics disorder, nonverbal learning disability, and reading disability.

Reading disability is an important aspects in students learning process. Kemp, Smith, Segal (2012)explain that learning disabilities difficulties in reading:letter and word recognition, understanding words and ideas, reading speed and fluency, general vocabulary skills, letter and word recognition, understanding words and ideas, reading speed and fluency, and general vocabulary skills. Reading disability may be characterized by:1) difficulties in single word reading; 2) initial difficulties decoding or sounding out words;3) difficulties reading sight words;4) insufficient phonological processing; 5) expressive or receptive language difficulties; and difficulties with comprehension (SaskatchewanLearning, 2004).

Dyslexia is a learning disability that affects approximately ten percent of the population. Despite having average or above average intelligence, people with dyslexia have difficulty in reading, and in other language-based tasks such as writing and spelling (Miller, 2012). In other word, Tatman (2005) states that Dyslexia isa learning disability that causes problems with reading. Shaywitz and Shaywitz (2002) argue that dyslexia is characterized by an unexpected difficulty in reading in children and adults who otherwise possess the intelligence and motivation considered necessary for accurate and fluent reading.

The teacher has important role in helping students with Dyslexia (reading disabilities and difficulties). The good contribution from teacher can encourage and support the children or students in learning process (Ryan, 2004). From the explanation above, this paper will discuss clearly and completely about reading skill, reading disability and 
difficulty, dyslexia, causes of dyslexia, the characteristics children with dyslexia, and how can teachers help their students with dyslexia.

\section{THEORITICAL FRAMEWORK}

\section{THE CONCEPT OF READING}

Reading is an important skill that needs to be developed in children. Not only is it necessary for survival in the world of schools and universities, but in adult life as well. There are various definitions that have been stated by language expert. Reading is a complex cognitive and linguistic process. Nuttal (1982) states that definition of reading in three levels: 1). Reading is the process in decoding, deciphering, and identifying the printed words. 2) Reading is the process in articulating, speaking, and pronouncing the words in print. 3) Reading is the process in understanding, interpreting the meaning of text (p.2).

In other word, Grabe and Stoller (2002) explain that reading is the ability to draw meaning from the printed page and interpret the information appropriately (p.9). In addition, Alyousef (2005) defines that reading can be seen as an interactive process between a reader and a text which leads to automaticity or reading fluency. It involves decoding alphabetic symbols, drawing upon experiences and language, and using strategies effectively to make meaning. So, reading is very important to the students.

In addition, Nunan (2003) states that reading divided into two types, strategic reading, and fluent reading (p.68). Strategic reading is defined as the ability of the reader to use a wide variety of reading strategies to accomplish a purpose of reading. However, fluent reading is defined as the ability to read at an appropriate rate with adequate comprehension both of those reading skills is important and related each other.

Based the explanation above, it can be say that reading as the process that is used to understand information presented in written form and people are able to read if the words printed can be identified by the reader. Reading improves their grasping skills and sharpens their 
analyzing and problem-solving abilities. Reading gives them knowledge, making them more confident.The more students read, the better developed their cognitive abilities.

\section{Reading Disabilities and Difficulties}

Reading is the process of extracting meaning from written symbolic characters. In elementary school, a large amount of time and effort is devoted to the complicated task of learning to read (American Academy of Pediatrics, Section on Ophthalmology, Council on Children, 2009). Reading is not easy subject for the students. It showed that the many of students have difficulties in reading. Kemp, Smith, Segal (2012)explain that learning disabilities or difficulties in reading: letter and word recognition, understanding words and ideas, reading speed and fluency, general vocabulary skills, letter and word recognition, understanding words and ideas, reading speed and fluency, and general vocabulary skills.

Learning disabilities or difficulties in reading may be characterized by: 1) difficulties in single word reading; 2) initial difficulties decoding or sounding out words; 3) difficulties reading sight words; 4) insufficient phonological processing; that is, the understanding that sentences are comprised of words, words are made up of syllables, and syllables are made up of individual sounds or phonemes; 5) expressive or receptive language difficulties; and 6) difficulties with comprehension (Saskatchewan Learning, 2004).From the explanation above, it can be said that reading disabilities and difficulties can effect students ability in some aspect of language.

\section{The Concept of Dyslexia}

The first reference of the term dyslexia occured in 1872 by the physician R. Berlin of Stuttgart, Germany, who used the term to describe the case of an adult with acquired dyslexia, that is, loss of reading ability due to a brain lesion (Guardiola, 2001)Dyslexia is a term that has been applied since the early part of the 20th Century to many students with 
reading difficulties. The term comes from medicine, but its broadest application is within education (Torgeson, Foorman, \& Wagner, 2009).

Word Federation of Neurology (1970, cited in Clisby, Fowler, Hebb, Southcott \& Stein, 2000) explains that developmental dyslexia is a potent cause of children's misery and despair, but unfortunately very common 5-10\% of 8-10 year olds have exceptional difficulty learning to read despite conventional instruction, adequate intelligence, and sociocultural opportunity. Petterson and Pennington (2012) argue that dyslexia is a neurodevelopmental disorder that is characterized by slow and inaccurate word recognition.

Dyslexia is a learning disability that causes problems with reading, writing, and spelling (Tatman, 2005). Furthermore, dyslexia is often referred to as specific learning difficulty to show that it is not an all around learning problem. Dyslexia is a difficulty with words, but can involve more than just reading and spelling and can effect writing and number word (Hamsphire County Council, 2009). Equally, National Institute of Literacy said that Dyslexia is a type of learning disability. Specially, it is a language based disorder characterized by problems learning to read, write, spell, and decode single words (cited in South Dakota Department of Education, 2009).Rose (2009 cited in TDA, 2006) argues that dyslexia is a learning difficulty that primarily affects the skills involved in accurate and fluent word reading and spelling.

According to The International Dyslexia Association (cited in South Dakota Department of Education, 2009), dyslexia is a learning abilities that is neurological in origin. It is characterized by difficulties with accurate and or fluent word recognition and by poor spelling and decoding abilities. In other word, Bull (2006) explains that despite the emphasis on literacy difficulties, dyslexia would appear to include a wide range of symptoms including poor short term memory, dyscalculia, visual impairment, speech disorders, and poor motor control, as well as emotional difficulties such as poor self esteem, clinical depression, chronic anxiety, and conduct disorder. 
Ramus (2004) states that developmental dyslexia is a mild hereditary neurological disorder which manifest itself as a persistent difficulty in learning to read in children with otherwise normal intellectual functioning and educational opportunities. He explained that many reasearcher typically attempt to characteristise dyslexia at the genetic, neurobilogical and cognitive levels of decscription, and orther to uncover casual pathways between the different levels. In addition, Department for Education and Skills (2003) states thatDyslexia affects informationprocessing (receiving, holding,retrieving and structuringinformation) and the speed ofprocessing information.It thereforehas an impact on skills such asreading, writing, using symbols andcarrying out calculations.

\section{Causes of Dyslexia}

Dyslexia is a reading difficulties caused by neurological disorder. Guardiola (2001) definesthose two factors that cause of dyslexia: neurological and cognitive. Neurological factors: dyslexia is the late or abnormal development of literacy skill caused by a neurological difference, and for the most part shows itself as a different way of fuctioning.Cognitive factors: the low development of functioning attention, perception, memory, thinking, and language.

In addition, Ministry of Education classifiesthere are three main deficit theories on what causes the characteristics of dyslexia: 1) the phonological deficit theory explains difficulties dyslexic, 2) individual show linking sounds with symbols in reading and spelling, 3) The cerebelladeficit theory suggests there is a problem in central processing linked to learning and automaticity, 3) The magno-cellular deficit theory suggests that problems arise as a result of visual or auditory deficits.

The dyslexic brain is different from ordinary brains. Studies have showndifferences in the anatomy, organisation and functioning of the dyslexic brainas compared to the non-dyslexic brain.

"Some people suggest that dyslexic people tend to be more 'right brainthinkers'. The right hemisphere of the brain is associated with lateral, creativeand visual thought processes.Dyslexia is not 
related to race, social background or intellectual ability butthere is a tendency for dyslexia to run in families and this suggests that thebrain differences which cause dyslexia may be hereditary.These neurological differences have the effect of giving the dyslexic person aparticular way of thinking and learning. This usually means that the dyslexicperson has a pattern of cognitive abilities which shows areas of strengths andweaknesses (Department for Education and Skills, 2004).

From the explanation about, it can be said that, the mmain causes of dyslexia is neurological and cognitive disorder. In neurological disorder, the children have difficulties in reading because a disorder of their brain. In cognitive disorder, the children have difficulties in reading because they have a weakness in memories the word and also use the word in context.

\section{The Characteristics of Children with Dyslexia}

There are some characteristic of children with dyslexia. Hampshire County Council states that the characteristics of children with dyslexia may have had difficulty with: (1) learning to talk or pronouncing long words, (2) learning nursery rhymes, (3) dressing, especially than using buttons, zips, and sho laces, (4) colouring neatly and using scissors. In addition, Tatman (2005) states thatthe characteristics of children with dyslexia divided into two stage:early childhood and middle childhood with dyslexia.

Inearly childhood, the students have had: (1) Trouble learning to speak, (2) Difficulty rhyming, (3) Trouble learning the alphabet, numbers, and days of the week, (4) Difficulty telling a story in the correct order, (5) Trouble learning connection between letters and sounds. In middle childhood, the children have had: 1) Reads and writes 
letters in wrong order or backwards, 2)Confuses small words like "at" and "to", 3) Difficulty reading, spelling, learning foreign language, and/or doing math problems, 4) Difficulty organizing written and spoken language, 5) Relies on memorization, 6) Confuses math symbols, 7) Trouble understanding non-literal language including jokes, slang, etc., 8) Awkward pencil grip, 9) Difficulty organizing and managing time and tasks, 10) Difficulty summarizing, 11) Often misreads information, 12) Illegible handwriting, and 13) Reads slowly and inaccurately.

In other word, South Dakato Depatment of Education, 2009) divides that the characteristics of dyslexia into four defferent grade levels: (1) preschool or kindergarten, (2) Grade 1-3, (3) Grade 4-8, and (4) High school, college, and adult.The students possible difficulties with reading acquisition in preschool or kindergaten are: (1) delayed speech; (2) confusion with before or after, right or left, and so on; (3) mispronounced words: persistant baby talk; (4) difficulty with recognizing and producing rhymes; (5) difficulty remembering and following directions.

At Grade 1-3 level,students with dyslexia will show some of the following characteristics: (1) difficulty remembering names or shapes of letters; (2) difficulty acquiring vocabulary or using age appropriate grammar; (3) difficulty putting ideas on paper; (4) reverses letters or the order of letters when reading; (5) inability to learn to associate letters with sounds; (6) confusion of visually similar letter; (7)Confusion of auditory similar letters; (8) Difficulties remembering basic sight vocabulary; (9) Problems with segmenting words into individual sound and blending sounds to form words; (10) Reading and spelling errors that involve difficulties with sequencing and monitoring sounds/symbol correspondence such as reversals of letters, omissions, additions, substitutions and transpositions; (11) Omission of grammatical endings in reading; (12) Difficulty remembering spelling words over time and applying spelling rules; (13) Inability to read common one-syllable words or to sound out even the simplest of words.

In the 4-8 grade level, the students have difficulties: 1) Difficulty understanding concepts and relationships, 2) Significant difficulty 
reading and spelling multisyllabic words, often omitting entire, 3) syllables as well as making single sound errors, 4) Lack of awareness of word structure, 5) Frequent misreading of common sight words (where, there, what, then, when, etc.), 6) Difficulties with reading comprehension and learning new information from text because of underlying word recognition difficulties, 7) If underlying oral language problems exist affecting vocabulary knowledge and grammar, difficulties in comprehension of text will occur, 8) Significant difficulties in writing related to problems in spelling as well as organizing ideas.

The last level is High school, college, and adult. The characteristics of students with dyslexia: 1) Continued difficulties with word recognition which significantly affect acquisition of knowledge and ability to analyze written material, 2) Slow rate of reading , 3) Continued difficulties with spelling and written composition, 4) Difficulty with note taking in class, and 5) Trouble learning a foreign language.

Many learners withdyslexia have the followingcharacteristics that may impact ontheir learning, though not all dyslexiclearners will have all thesecharacteristics (Department for Education and Skills, 2003): 1) Difficulties in organizing work; 2) A poor sense of the passage of time,mixing up dates and times andmissing appointments, 3) Directional confusions, getting losteasily and having problems usingmaps or finding the way to a new place, 4) Difficulty in achieving automaticitywhen they have to do more thanone thing at a time, as in taking notes, 5) Difficulty in carrying outinstructions, copying from theboard and remembering what hasjust been read or said, takingmessages, remembering phonenumbers and dialing numbers accurately, 6) Poor motor control, resulting indifficulties in controlling a pen, 7) Difficulties in recognizing, orconfusion between, letters orfamiliar words when reading orremembering the visual image ofwords, signs, or symbols, 8) Mispronunciations caused bydifficulties in discriminating between sounds, 9) Difficulties in reading text causedby visual distortions, and 10) Problems with sequencing such aswith 
instructions or sequences ofnumbers or letters and difficultiesusing dictionaries, encyclopediasand directories.

\section{How Can I Help My Students with Dyslexia?}

Teacher is one important people that can help the children with dyslexia. The children can get the good way in teaching reading to solve their problem in dyslexia. Torgeson, Foorman, \& Wagner (2009) state that school instruction to prevent of reading a difficulty in students with dyslexia is Response to Intervention (RTI). This instruction has three important elements: 1) Classroom teachers that provide high quality initial instruction along with small group instruction that is differentiated according to student needs; 2) Reliable screening and progress monitoring tests to identify students falling behind in reading growth; and 3) Interventions for struggling readers that are sufficiently powerful to accelerate their reading development toward grade level standards.

Bienge (2011) states that some tasks that we use regularly in class can act as triggers for behavioral problems and can help us to identify if a student has a learning difficulty such as: 1) Asking students to read aloud in class, 2) Silent reading, 3) Locating info in a dense text, 4) Asking for verbal answers, 5) Dictating notes, 6) Extended periods of listening, 7) Time limits on tasks, 8) Lots of copying or writing at length, and 9) Requiring students to work alone.

In relation to dyslexia, schools should work to promote the underpinning principles of effective Special Educational Needs (SEN) policy, provision and practice. These focus on: raising attainment, equality of opportunity, early intervention, working in partnership with parents / careers, inclusive education (that is, enabling all children as far as possible, to learn, together, in ordinary schools with appropriate support), overcoming barriers to learning, and a coherent support framework for school staff (Devon County Council, 2011). 
There are some following strategies to help the students with dyslexia (National Centre for Learning Disabilities): 1)Expose your child to early oral reading, 2) have your child practice reading different kinds of texts, 3) Include multi-sensory, 3) structured language instruction, 4) Seek modifications in the classroom, 5) Use books on tape and assistive technology, and 6) Get help with the emotional issues that arise from struggling to overcome academic difficulties. These strategy are believed can help the students with dyslexia.

\section{CONCLUSION}

From the explanation above, it can be concluded that: 1) Dyslexia is a mild hereditary neurological disorder which manifest itself as a persistent difficulty in learning to read in children with otherwise normal intellectual functioning and educational opportunities; 2) there are two crucial factors of dyslexia causes: neurological and cognitive factor; 3) the characteristics of children with dyslexia divided into two stages: early childhood (preschool or kindergarten, Grade 1-3, and Grade 4-8) and middle childhood with dyslexia(High school, college, and adult); and 4) teacher has important role in teaching for the students with reading disabilitiesand difficulties (dyslexia). Teacher can guide the student in learning, give them an interesting activities by using good strategy.

\section{REFERENCES}

Alyousef, H. (2005). Teaching reading comprehension to ESL/EFL learners. The Reading Matrix5(2). Retrieved from www.ala.org/ala/mgrps/divs/acrl/..../Bordonaro.pdf.

Biengge, H. (2011). Learning a second language when your first is a struggle.

Retrieved fromhttp://iatefl.britishcouncil.org/2011/sites/iatefl/files/session 
/documents/hannah bienge learning a 2nd language when your 1 st is a struggle handout.pdf.

CAPLAN, D. (1995). Language and the brain. Retrieved from http://www.hms.harvard.edu/hmni/On The Brain/Volume04/Nu mber4/F95Lang.html.

Clisby, C., Fowler, M.S., Hebb, G.S., Southcott, P., \& Stein, J.F. (2000). Outcome of treatment of visual problems in children with reading difficulties. PATOSS, _(), 9-14. Retrieved fromhttp://www.dyslexic.org.uk/docs/Visual\%20Problems\%2002-11-18.pdf.

Dangerfield, A. (2010). Things parents can do to help their children. Retrieved from http://www.dyslexia.ie/wpcontent/uploads/2010/12/Conf-2010-Anna-Dangerfield.pdf.

Hampshire County Council. (2009). Specific learning difficulties (dyslexia). Retrieved from http://www3.hants.gov.uk/dyslexia leaflet.pdf.

Guardiola, J.G. (2001). The evolution of research on dyslexia. Institute for Behavioural Genetics and Department of Psychology, University of Colorado. Retrieved from http://ibgwww.colorado.edu/ gayan/ch1.pdf.

Grabe, W. \& Stoller, F. (2002). Teaching and Researching Reading. Edinburh Gate, England: Pearson Education Limited.

Gyarmathy, E. (_). Causes of dyslexia. Retrieved from http://www.diszlexia.hu/VETOenglish/Causes\%20of\%20dyslexia.p df.

Kemp, G., Smith, M., \& Segal, J. (2012). Learning Disabilities in Children. Retrieved fromhttp://www.helpguide.org/mental/learning disabilities.htm.

Lyon, G.R. (1996). Learning Disabilities. The Future of Children Special Education For Students With Disabilities, 6(1), 54-76. Retrieved from http://www.princeton.edu/futureofchildren/publications/docs/06 01 03.pdf. 
National centre of Learning Disability. _. What is dyslexia. Retrieved from http://www.ncld.org/types-learningdisabilities/dyslexia/what-is-dyslexia.

Nunan, D. (2003). Practical English Language Teaching. 2003. Singapore: McGraw Hill.

Nuttall, C. (1982). Teaching Reading Skills in a Foreign Language. Heinemann.

Peterson, R.B., \& Pennington, B.F. (2007). Developmental dyslexia. Lancet, _(379), 1997-2007.

Retrieved fromhttp://pediatrics.uchicago.edu/chiefs/DBP/documents/readin g\%20pdf/Dyslexia.Peterson.pdf.

Rumus, F. (2004). Neurobiological of dyslexia: a reinterpretation of the data. Trends in Neurosciences, 27(12), 1-9. Retrieved fromhttp://www.lscp.net/persons/ramus/docs/TINS04.pdf.

Ryan, M. (2004). Social and emotional problems related dyslexia. Retrieved fromhttp://www.ldonline.org/article/19296/.

Saskatchewan Learning. (2004). Teaching students with reading difficulties and disabilities. Retrieved from http://www.education.gov.sk.ca/reading-difficulties-disabilities.

Shaywittz, S.E., \& Shaywitz. (2003). Dyslexia (specific reading disability). Pediatrics in Review, 24(5), 147-153. Retrieved fromhttp://www.mydoctor.ca/documents/users/3428/8466.pdf.

South Dakota Department of Education. (2009). The dyslexia handbook for teachers and parents in South Dakota. Retrieved fromhttp://doe.sd.gov/oess/documents/SPED DyslexiaGuide.pdf.

Tatman, P. (2005). Youth and dyslexia. Department of Family and Consumer Sciences, University of Wyoming. Retrieved fromhttps://uwadmnweb.uwyo.edu/wyo4h/inclusive/dyslexia.pdf.

Torgesen, J.K., Foorman, B.R., \& Wagner, R.K. (2007). Dyslexia: a brief for educators, parents, and legislators in Florida. Retrieved 
200 | ENGLISH FRANCA, Vol. 2, No. 2, 2018

fromhttp://www.fcrr.org/TechnicalReports/Dyslexia Technical As sistance Paper-Final.pdf. 